\title{
The Role of Moisture Pathways on Snowfall Amount and Distribution in the Payette Mountains of Idaho
}

\author{
MATTHEW D. CANN AND K. FRIEDRICH \\ Department of Atmospheric and Oceanic Sciences, University of Colorado Boulder, Boulder, Colorado
}

(Manuscript received 21 October 2019, in final form 2 March 2020)

\begin{abstract}
The pathways air travels from the Pacific Ocean to the Intermountain West of the United States are important for understanding how air characteristics change and how this translates to the amount and distribution of snowfall. Recent studies have identified the most common moisture pathways in the Intermountain West, especially for heavy precipitation events. However, the role of moisture pathways on snowfall amount and distribution in specific regions remains unclear. Here, we investigate 24 precipitation events in the Payette Mountains of Idaho during January-March 2017 to understand how local atmospheric conditions are tied to three moisture pathways and how it impacts snowfall amount and distribution. During one pathway, southwesterly, moist, tropical air is directed into the Central Valley of California where the air is blocked by the Sierra Nevada, redirected northward and over lower terrain north of Lake Tahoe into the Snake River Plain of Idaho. Other pathways consist of unblocked flows that approach the coast of California from the southwest and then override the northern Sierra Nevada and southern Cascades, and zonal flows approaching the coast of Oregon overriding the Oregon Cascades. Air masses in the Payette Mountains of Idaho associated with Sierrablocked flow were observed to be warmer, moister, and windier compared to the other moisture pathways. During Sierra-blocked flow, higher snowfall rates, in terms of mean reflectivity, were observed more uniformly distributed throughout the region compared to the other flows, which observed lower snowfall rates that were predominantly collocated with areas of higher terrain. Of the total estimated snowfall captured in this study, $67 \%$ was observed during Sierra-blocked flow.
\end{abstract}

\section{Introduction}

Every winter, the fate of the American West hinges on the mountains accumulating enough snowpack to prevent water shortages and ensuing social, economic, and ecological dilemmas. These dilemmas are of great concern in Idaho, a state that generates as much as $75 \%$ of its power from hydroelectric plants that depend heavily on spring and summer runoff from snowpack (U.S. Energy Information Administration 2016). The meltwater from winter snowfall also provides crucial supply for the agricultural industry and the fish and wildlife industries, all vital for Idaho's economy. Thus, understanding how much and where snow falls in the mountains and how snowfall is linked to large-scale weather patterns may aid in anticipation of runoff to manage flood risk, reservoir operations, and hydroelectric plants. Recently, attention has been directed to the pathways moist air travels from the Pacific Ocean to the Intermountain

Corresponding author: Matthew D. Cann, matthew.cann@ colorado.edu
West (Alexander et al. 2015; Rutz et al. 2015). While these studies have identified common moisture pathways and changes in atmospheric conditions in a broad sense, less attention has been given to how pathways and associated changes in dynamics and thermodynamics play a role in snowfall amount and distribution in localized regions of the Intermountain West. To fill this gap in knowledge, this study focuses on a multiscale analysis showing how moisture travels from the Pacific Ocean to the Payette Mountains region of Idaho's Central Mountains (Fig. 1) and how it relates to atmospheric conditions and snowfall amounts and distributions. We use atmospheric measurements from 24 precipitation events collected between January and March 2017 during the Seeded and Natural Orographic Wintertime clouds: the Idaho Experiment (SNOWIE) in the Payette Mountains to understand the role of moisture pathways on snowfall.

One common moisture pathway to the Payette Mountains is through California's Central Valley (hereafter CV), where air is blocked by the Sierra Nevada, becomes entrained in the Sierra barrier jet, and is lofted over the lower terrain between Lake Tahoe and the Burney Gap (Fig. 1a; 




FIG. 1. (a) Topographic map of the American West with terrain features discussed in the text. (b) Instrument location within the radar observational domain centered around the PJ DOW radar. The radar range is shown by the $50 \mathrm{~km}$ radius circle.

Alexander et al. 2015; Rutz et al. 2015; White et al. 2015, Swales et al. 2016). The Burney Gap is an area of relatively lower terrain in the southern Cascade Range, near Burney, California, at the northeastern corner of the CV. This gap and the lower terrain extending to Lake Tahoe is important for precipitation in certain regions of the Intermountain West because it allows for moist air to penetrate farther inland to the Snake River Plain of Idaho generally unobstructed by large terrain features (Alexander et al. 2015; Rutz et al. 2015). The Sierra barrier jet redirects moist flow parallel to the range (i.e., south-southeasterly flow), opposed to lifting it over the Sierra Nevada, and directs strong, horizontal moisture flux to the northern CV (Neiman et al. 2013; Neiman et al. 2014; White et al. 2015; Ralph et al. 2016). However, it is unknown what quantity of moist, Sierraparallel flow is directed out of the CV into the Snake River Plain. The other common moisture pathways to the Payette Mountains include flow rising above the Sierra barrier jet and subsequently over the Sierra Nevada (Neiman et al. 2013; their Fig. 13) and flow making landfall farther to the north and rising over the Coast Ranges and Cascades of Oregon (Alexander et al. 2015; their Fig. 3). The aforementioned studies have developed a conceptual understanding of thermodynamic changes that occur at landfall and along different moisture pathways into the Intermountain West but the scientific community has not yet established relationships between the resulting atmospheric environments in different moisture pathways and the interaction with local terrain and the effects local precipitation patterns.

Many wintertime-precipitation studies in the West have established a relationship between integrated water vapor transport (hereafter IVT) and precipitation amount (e.g., Rutz et al. 2014; Swales et al. 2016; Ralph et al. 2019). For example, IVT is well-correlated $(r \sim 0.6)$ with wintertime precipitation amounts in the Payette Mountains, explaining $30 \%-40 \%$ of the variance in daily precipitation amounts (Rutz et al. 2014). IVT is also used to identify atmospheric rivers, long narrow corridors of enhanced water vapor flux that is transported from the tropics to the midlatitudes (Zhu and Newell 1998; Ralph et al. 2004; Gimeno et al. 2014; Ralph et al. 2019). Atmospheric river conditions are defined as IVT $\geq 250 \mathrm{~kg} \mathrm{~m}^{-1} \mathrm{~s}^{-1}$ at landfall (Rutz et al. 2014; Ralph et al. 2019). Storms with larger moisture content and stronger winds (i.e., higher IVT), more amplified troughs and more southwesterly than westerly flow at landfall have been shown to penetrate farther inland (Rutz et al. 2015). The largest number of these high IVT storms are observed in November along the northwestern United States and farther south along the West Coast in December-February (Rutz et al. 2014) as the southward propagating polar jet stream determines the landfall location of these storms.

Given how the landfall location and subsequent moisture pathways into the Intermountain West are affected by interannual variability and climate change-induced shifts in the jet stream, it is essential to understand how large-scale moisture transport modulates regional atmospheric conditions and snowfall patterns. Between 1979 and 2001, the polar and subtropical jet streams have moved poleward in both the northern and Southern Hemispheres (Archer and Caldeira 2008), implying a general poleward shift in landfalling storms. Future climate simulations of atmospheric rivers events on the U.S. West Coast suggest that a global warminginduced strengthening of the subtropical jet stream may increase the frequency of landfalling atmospheric rivers in the $32^{\circ}-35^{\circ}$ latitude band with slight decreases at other latitudes (Shields and Kiehl 2016; and references therein). However, as the impact of climate change on storm track remains largely uncertain (Shaw et al. 2016), this study aims to identify the moisture pathways that lead to higher snowfall amounts in the Payette Mountains to aid in anticipating water budgets in future climate scenarios and on a year-to-year basis.

In this study, we utilize observations from SNOWIE to provide insight on how natural snowfall patterns are tied to moisture pathways and how glaciogenic cloud seeding operations may be maximized by understanding atmospheric conditions based on moisture pathways. While SNOWIE focused on the impact of cloud seeding, it also aimed at understanding the natural snowfall processes in the Payette Mountains and how those natural cloud processes are altered or replicated by glaciogenic cloud seeding via aircraft. The SNOWIE field 
campaign was conducted between 7 January and 17 March 2017 in the Payette Mountains of Idaho, $\sim 65 \mathrm{~km}$ north of Boise (Fig. 1; Tessendorf et al. 2019). A total of 24 intensive observational periods (IOPs) were completed with observations taken from airborne and groundbased in situ and remote sensing instruments. This portion of the winter season was particularly interesting as precipitation in the Payette Mountains was around the 30-yr climatological median in early January 2017 and in the 95th percentile in late March 2017 (Tessendorf et al. 2019). Four questions are addressed in this study; 1) During SNOWIE, which moisture pathways were observed? 2) Do moisture pathways vary during IOPs? 3) What are the differences in local thermodynamics and dynamics tied to each pathway? and 4) How do pathways modulate the amount and distribution of snowfall?

We address these questions through a multiscale analysis of moisture pathways and moisture fluxes using numerical weather model and reanalysis data, local observations of dynamics and thermodynamics, and precipitation observations from ground-based dualpolarization radar in the Payette Mountains. The paper is organized to describe, in section 2 , the methods and tools of how to 1) determine the pathways and their atmospheric properties, 2) analyze dynamics and thermodynamics in the Payette Mountains associated with each pathway, and 3) analyze the snowfall amount and distribution in the Payette Mountains. Using the same structure as the methods, we then present the results of our analysis in section 3 . The paper synthesizes the results with a discussion in section 4 and summary on the role of moisture pathways on snowfall amount and distribution in the Payette Mountains in section 5.

\section{Instruments and methods}

\section{a. Defining moisture pathways and moisture fluxes}

To identify the pathways moisture travels from the Pacific Ocean to the Payette Mountains, we utilized a Lagrangian analysis to track the location of a particle in space and time. We employed the NOAA Hybrid SingleParticle Lagrangian Integrated Trajectory (HYSPLIT; Stein et al. 2015; Rolph et al. 2017) model to run backward trajectories at the beginning of each hour during an IOP. During SNOWIE, an IOP was defined as $30 \mathrm{~min}$ prior to research aircraft operation to $30 \mathrm{~min}$ after landing. Since backward trajectories are only available at the beginning of each hour, analyses using higher temporal resolution observational data were averaged $\pm 30 \mathrm{~min}$ about the hour. We acknowledge that airflow can be highly variable in space and time and that tracking of a single particle is not necessarily indicative of dynamic atmospheric flow for an entire hour. Therefore, we additionally used the ensemble feature in HYSPLIT which creates 27 spatially offset trajectories for each hour for a 20-h subset of complex airflow during IOPs 4 and 15 and compared it to our single hourly trajectory. To overcome some of the uncertainties in the backward trajectory analysis, the results of the analyses are carefully considered using statistical significance and confidence interval thresholds to identify differences linked to each pathway. The trajectories start at $700 \mathrm{hPa}(\sim 3 \mathrm{~km}$ MSL) above Packer John Mountain, the SNOWIE ground-based radar site described in section 2c (hereafter PJ; $2138 \mathrm{~m}$ MSL; Fig. 1b). Note that we expect $3 \mathrm{~km}$ MSL $(<1 \mathrm{~km}$ above local mountain crests) to be near a maximum in horizontal moisture transport (Neiman et al. 2002; Mahoney et al. 2018). Additionally, choosing $700 \mathrm{hPa}$ allows us to place our results in the context of other studies (Alexander et al. 2015; Rutz et al. 2015) by matching their methodologies. HYSPLIT uses threedimensional model winds from the High-Resolution Rapid Refresh (HRRR) model to calculate trajectories, which track backward in time for $72 \mathrm{~h}$ or until the trajectory reaches the boundary of the HRRR domain, which typically occurs between $125^{\circ}$ and $130^{\circ} \mathrm{W}$. The HRRR was chosen over other model datasets available within HYSPLIT for its high spatial resolution $(3 \mathrm{~km})$, which we expect to best represent the complex terrain and terrain-induced flows (e.g., Sierra barrier jet). Backward trajectories were calculated using the HRRR model data in HYSPLIT for each hour of an IOP for all 24 IOPs, totaling 158 trajectories (Fig. 2).

To classify the backward trajectories, we used the following objective criteria. First, we determined if the flow in the HRRR model was redirected to the north by the Sierra Nevada, an indication of blocked flow. To be considered blocked flow, the trajectory must 1) be located within the CV (i.e., between the Sierra Crest and Coast Ranges of California; Fig. 1a), 2) be below an altitude of $2.5 \mathrm{~km} \mathrm{MSL}$, and 3) exhibit a wind direction within $40^{\circ}$ of the crest-parallel flow $\left(160^{\circ}\right)$ used to identify Sierra barrier jets in Neiman et al. (2013). All three conditions must be satisfied for a minimum of two consecutive hours to be considered blocked flow. The $2.5 \mathrm{~km}$ MSL altitude restriction was based on the $3 \mathrm{~km}$ MSL height of the Sierra Crest, as in Neiman et al. (2013), with reduced altitude to reflect the height of the Sierra Crest in the HRRR model. Sierra barrier jets typically exhibit veering winds with height with more along-barrier flow at low levels and stronger crossbarrier flow aloft (Neiman et al. 2013). Therefore, a $40^{\circ}$ window about the crest-parallel flow direction is used to allow for variation in the wind direction with 


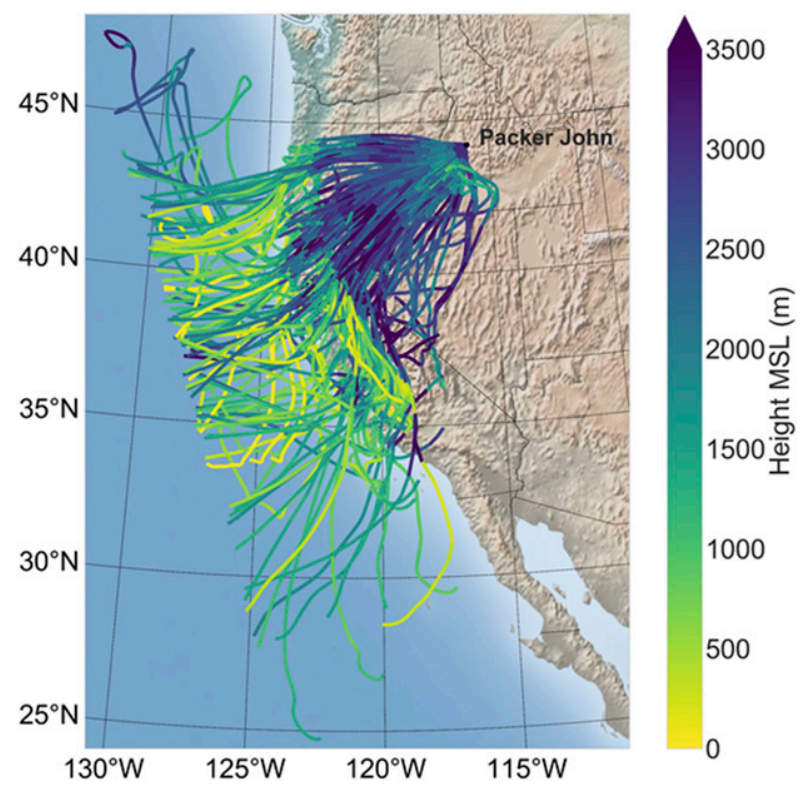

FIG. 2. Height of backward trajectories initiated at PJ during all 24 SNOWIE IOPs (158 trajectories).

height. The window was chosen to be $40^{\circ}$ because it was able to capture the altitudinal variation within this flow while separating the overriding flow. We tested the sensitivity of these criteria using a 270-trajectory ensemble of $10 \mathrm{~h}$ of airflow during IOP 4 . Changing the height criteria by $\pm 500 \mathrm{~m}$ resulted in the same pathway categorization $99 \%$ of the time. Whereas Widening/tightening the wind direction window by $10^{\circ}$ ( $5^{\circ}$ on either end) and using 1 or $3 \mathrm{~h}$ of consecutive blocking resulted in the same pathways categorization $93 \%$ and $90 \%$ of the time, respectively. These criteria determined the first group of trajectories, which is referred to as Sierra-blocked or SB flow.

The remaining trajectories not blocked by the Sierra Nevada, exhibit characteristics of overriding flow that lifts over SB flow or simply overriding mountain ranges in Northern California and Oregon (Neiman et al. 2013; their Fig. 13). We categorized the unblocked trajectories based on their mean wind direction over land. If the mean wind direction is southwesterly $\left(202.5^{\circ}-247.5^{\circ}\right.$ ), trajectories are categorized as southwest or SW flow and if the mean wind direction is westerly $\left(247.5^{\circ}-292.5^{\circ}\right)$, trajectories are categorized as zonal flow. In addition to these three flow patterns, there was one occurrence of a trajectory with southerly flow $\left(157.5^{\circ}-202.5^{\circ}\right)$, which was omitted due to the low frequency of this pathway during SNOWIE. In addition, six trajectories did not make it back to the Pacific Ocean during the 72-h HYSPLIT runtime and were not categorized. Thus, 151 of the total 158 trajectories are analyzed further in this study.
In addition to using the HRRR model to calculate the backward trajectories, we used hourly HRRR analyses (Blaylock et al. 2017) to understand which trajectories result in the highest moisture transport at PJ. Moisture transport in the form of IVT was calculated using

$$
\mathrm{IVT}=\frac{1}{g} \int_{1000 \mathrm{hPa}}^{300 \mathrm{hPa}} q V d p
$$

where $g$ is gravitational acceleration $\left(9.8 \mathrm{~m} \mathrm{~s}^{-2}\right), q$ is the specific humidity in $\mathrm{kg} \mathrm{kg}^{-1}, V$ is the magnitude of the wind $\left(\mathrm{m} \mathrm{s}^{-1}\right)$, and $p$ is the pressure in $\mathrm{hPa}$. Note that when the surface extends above $1000 \mathrm{hPa}$ the integration was performed from the surface to $300 \mathrm{hPa}$. Additionally, moisture flux $(q V)$ was calculated at each pressure level to provide a vertical structure of the moisture transport at PJ. We used the HRRR dataset for this analysis because hourly observations of moisture and wind were not available for necessary levels of the atmosphere.

The atmospheric conditions during SB, SW, and zonal flow were compared using the North American Regional Reanalysis (NARR) ${ }^{1}$ dataset to identify differences in the large-scale circulation patterns associated with each pathway. The NARR uses the 32-km spatial resolution National Centers for Environmental Prediction Eta Model with Regional Data Assimilation System (RDAS). It is important to note that the NARR has 3-h temporal resolution, which reduces the sample size from 1-h temporal resolution to 3 -h temporal resolution or by $\sim 2 / 3$. The NARR was chosen instead of a higher temporal resolution dataset (e.g., HRRR) because of its larger domain over the eastern North Pacific Ocean. Once the pathways and largescale patterns are identified, we investigated the impact of each pathway regime on observed local conditions in the Payette Mountains.

\section{b. Defining thermodynamics and dynamics through radiometer and rawinsondes}

Observations from a microwave radiometer (hereafter MWR) and rawinsondes were used to understand differences in local dynamics and thermodynamics associated with each pathway. During SNOWIE, a Radiometrics MWR-3000A was located in a valley $10 \mathrm{~km}$ north of PJ (1386 m MSL; Fig. 1b). Microwave emissions at the water vapor $(22-30 \mathrm{GZ})$ and oxygen $(51-59 \mathrm{GHz})$ absorption band together with infrared emission at 9.6-11.5 microns were used to retrieve vertical profiles of temperature, water vapor density, and relative humidity every $2-3$ min using

\footnotetext{
${ }^{1}$ NCEP-NARR data are provided by the NOAA/OAR/ESRL PSD, Boulder, Colorado, USA, from their website at https:// www.esrl.noaa.gov/psd/.
} 
historic radiosondes and a regression method and neural network (Solheim and Godwin 1998; Solheim et al. 1998; Ware et al. 2003). The algorithm, based on a radiative transfer model (Rosenkranz 1998), was trained for the MWR on a 5-yr radiosonde climatology from the Boise, Idaho, National Weather Service sounding archive. Note that the MWR observes within in an inverted cone with a $2^{\circ}-3^{\circ}$ beamwidth at $51-59 \mathrm{GHz}$, and $5^{\circ}-6^{\circ}$ beamwidth at 22-30 GHz (Ware et al. 2003). MWR profiles were observed at zenith and at an elevation angle of $15^{\circ}$ and $45^{\circ}$ above the ground toward the north and south. It has been observed that retrieved temperature and humidity profiles from the $15^{\circ}$ and $45^{\circ}$ off-zenith observations provide higher accuracy during precipitation compared to the zenith observations by minimizing the effect of liquid water and ice on the MWR radome (Xu et al. 2014). Comparison to tower and sounding data have indicated that differences in temperatures are below $1.5^{\circ} \mathrm{C}$ (Friedrich et al. 2012; Bianco et al. 2017). The vertical resolution of the retrieved profiles ranged from $50 \mathrm{~m}$ between the surface and $0.5 \mathrm{~km}$ AGL; $100 \mathrm{~m}$ between 0.5 and $2 \mathrm{~km}$ AGL; and $250 \mathrm{~m}$ between 2 and $10 \mathrm{~km}$ AGL. MWR data on 2-3-min temporal resolution were averaged to match the hourly resolution of the trajectory analysis. Data presented in this paper are from the $45^{\circ}$ south beam to orient the data above PJ and due to the increased accuracy of the angled beams during precipitation compared to the zenith beam.

Rawinsondes launched during SNOWIE provide an additional source of thermodynamic data and information on atmospheric dynamics observed near PJ. During IOPs, Lockheed Martin Sippican LMS-6 rawinsondes were launched from a valley $10 \mathrm{~km}$ southeast of PJ (1083 m MSL; Fig. 1b). The soundings use a chip thermistor temperature sensor and LMU6 humidity sensor and GPS tracking to calculate wind speed and direction. Thermistor accuracy is reported as $\pm 0.2^{\circ} \mathrm{C}$ and humidity sensor uncertainty of $\pm 3 \%$ relative humidity (Nash et al. 2011 and references therein). Soundings were launched on a quasi-regular schedule of every 2-4h during IOPs. These observations of thermodynamic and dynamic conditions along with precipitation data were used to understand how snowfall is generated in this region.

\section{c. Precipitation observing system}

We used ground-based scanning radar to identify the intensity and location of falling precipitation in the Payette Mountains. Radar measurements were taken using a Doppler on Wheels (DOW) X-band dual-polarization, dual-frequency radar deployed at the summit of PJ mountain (2138m MSL; Fig. 1b). The DOW radar performed Plan Position Indicator (PPI) volume scans covering $360^{\circ}$ in azimuth and ranging from $-1^{\circ}$ to $69^{\circ}$ in elevation (Fig. 4-black boxes). Depending on the depth of the clouds observed, higher elevation angles were not used in all volumes, thus volume scan durations ranged from $3-10 \mathrm{~min}$. To not overrepresent precipitation from scans with shorter durations, radar data were time weighted based on the duration of each volume scan. Range resolution was chosen to be $50 \mathrm{~m}$, with 1000 range gates resulting in a maximum range of $50 \mathrm{~km}$. The DOW radar provides equivalent reflectivity from the horizontal channel $Z_{e}$, differential reflectivity $Z_{\mathrm{DR}}$, differential propagation phase $\phi_{\mathrm{DP}}$, and copolar correlation coefficient $\rho_{\mathrm{HV}}$. Using temperature observations from the MWR, a mesonet station collocated with the DOW radar, and soundings, we removed radar volumes when any height in the atmosphere was warm enough to produce rain (i.e., $T>0^{\circ} \mathrm{C}$ ) and subjectively verified that no melting layer (or brightband) was observed by the DOW radar. As a result, we have removed data from IOPs 2, 13, 23, and 24 completely and data after 1700 UTC in IOP 22 from our analysis. Thus, we used data from an 81-h subset of the 151 categorized hours in the precipitation portion of this study.

To ensure reliable measurements of precipitation, the DOW radar data required quality control and postprocessing in the form of correcting radar variables using calibration scans during and after SNOWIE and removal of ground clutter and nonprecipitating echoes using a fuzzy logic algorithm. Between volume scans, the DOW radar performed $360^{\circ}$ azimuthal scans at the $89^{\circ}$ elevation angle to calculate a $Z_{\mathrm{DR}}$ offset. The average offset for each IOP was calculated and applied to the radar retrieved $Z_{\mathrm{DR}}$ values with uncertainty of $\pm 0.2 \mathrm{~dB}$. After SNOWIE, the DOW radar was collocated with the KFTG WSR-88D radar near Denver, CO during 18 precipitating cases. Using the $1.0^{\circ}$ beam of the DOW radar to match the WSR-88D, a $Z_{e}$ offset for the DOW radar was calculated as $+7.6 \pm 1 \mathrm{~dB} Z_{e}$ and applied to the SNOWIE dataset. After postcalibration of $Z_{e}$ and $Z_{\mathrm{DR}}$, ground clutter and nonprecipitating echoes were removed using a fuzzy logic algorithm adapted from Gourley et al. (2007) following the technique of Aikins et al. (2016). The technique uses spatial variability in terms of root-mean-square difference and density functions of $Z_{\mathrm{DR}}, \rho_{\mathrm{HV}}$, and $\phi_{\mathrm{DP}}$. Some residual ground clutter, not eliminated by the declutter algorithm, was removed by identifying 10 independent volume scans with generally low $Z_{e}$ and subjectively identifying pixels of higher $Z_{e}$. Each of the 10 volumes scans used unique $Z_{e}$ thresholds based on $Z_{e}$ of the precipitation and pixels identified as ground clutter using this method were masked out of every volume scan. Finally, the radar data were mapped onto a three-dimensional Cartesian coordinate grid using Radx2Grid software developed at the National Center for Atmospheric Research 
a)

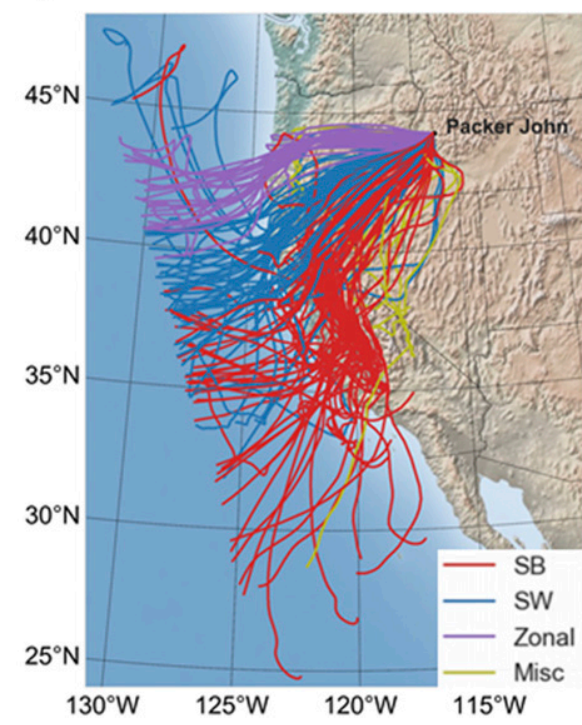

b)

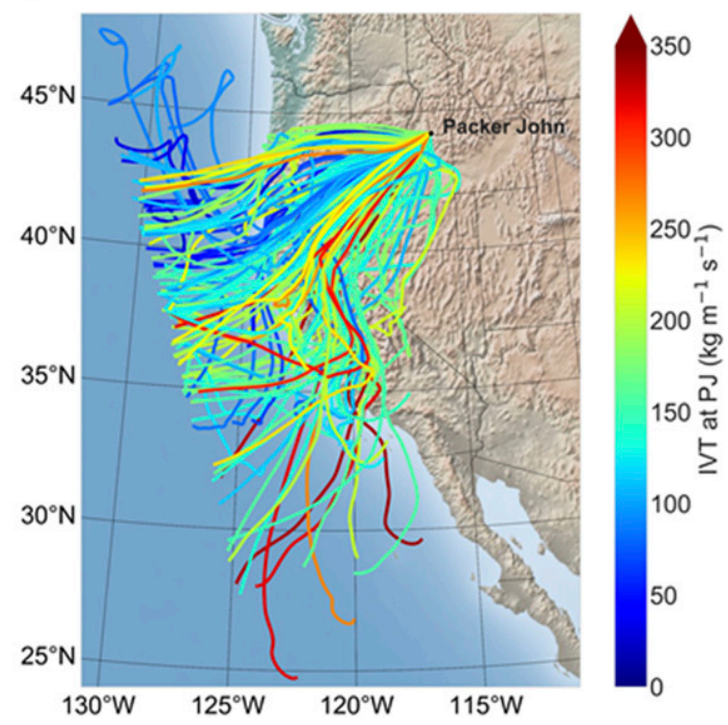

FIG. 3. (a) Pathways of the objectively categorized backward trajectories starting at PJ and (b) resulting IVT at PJ using HRRR analyses. Each trajectory is grouped either into Sierra-blocked (red lines), southwest (blue lines), and zonal flow (purple lines). Trajectories that do not fit any of the categories are indicates as miscellaneous (yellow lines).

(NCAR). The grid has spatial resolution of $100 \mathrm{~m}$ in the horizontal and $200 \mathrm{~m}$ in the vertical between 1 and $10 \mathrm{~km}$ MSL.

The gridded dataset was used to calculate echo top height for each grid point in a volume scan to understand the depth of the precipitating cloud. Echo top was defined as the highest height where $Z_{e} \geq-14 \mathrm{~dB} Z_{e}$; this value is the WSR-88D's minimum detectable signal (Lakshmanan et al. 2013). The distribution of echo top heights in each pathway provides insight into differences in cloud depth associated with each pathway.

We then calculated a temporally averaged $Z_{e}$ across the horizontal extent of the domain to estimate the average snowfall intensity and distribution using the maximum $Z_{e}$ below $4 \mathrm{~km}$ MSL. We used this method because the low-altitude angle radar beams can experience partial beam blockage near the surface, especially in complex terrain, which can greatly reduce the observed $Z_{e}$. The authors acknowledge that the maximum $Z_{e}$ value between the surface and $4 \mathrm{~km}$ MSL does not necessarily represent the snow hitting the surface, and that snow may continue to grow or sublimate in the atmosphere below and is a source of uncertainty in our analysis. Additionally, conversion of $Z_{e}$ to snowfall rates $(S)$ depends on the snow characteristics and a large variety of $Z_{e}-S$ relationships and strategies to derive radar-based snowfall rates exist (e.g., Puhakka 1975; Wolfe and Snider 2012; Friedrich et al. 2020). Instead of using $S$, we used $Z_{e}$ as a relative metric to compare snowfall in each pathway as if the same $Z_{e}-S$ relationship was applied to all cases.

\section{Results}

\section{a. Moisture pathways and moisture fluxes}

To understand the linkage between moisture pathways, regional atmospheric conditions, and snowfall, we first categorized back trajectories initiated at PJ (Fig. 3a) at the beginning of each hour during the 24 IOPs. The first 9 IOPs were conducted in January, followed by 9 IOPs in February, and the final 6 IOPs in March. IOP durations range from 3 to $11 \mathrm{~h}$, and total $158 \mathrm{~h}$ (Fig. 4). Of the 158 back trajectories, 66 or $41.8 \%$ were classified in the SB pathway (red lines in Fig. 3a), 59 or $37.3 \%$ were classified in the SW pathway (blue lines in Fig. 3a), 26 or $16.5 \%$ were classified in the zonal pathway (purple lines in Fig. 3a), and 7 or $4.4 \%$ did not fit any category and were not classified (yellow lines in Fig. 3a). We find that 17 of the 24 IOPs $(70.8 \%)$ exhibit multiple pathways, suggesting that moisture pathways are dynamic and can often change, even multiple times, within a single storm system. The majority of the IOPs that contain only a single pathway (4 of 7) were identified as zonal flow, while two were identified as SW flow, and one as SB flow (Fig. 4). The results from the ensemble sensitivity test of a 20 -h subset showed that the majority of the 27 ensemble trajectories aligned with the single 


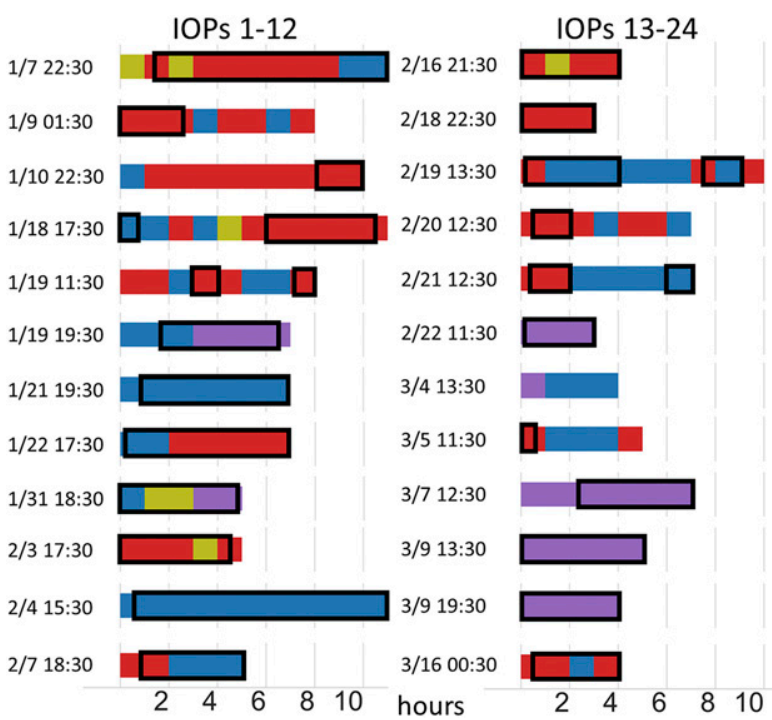

FIG. 4. Type of pathways (color coded) occurring during the 24 SNOWIE IOPs with start date and time ( $y$ axis) and duration ( $x$ axis). Sierra-blocked pathway is indicated in red, southwest pathway in blue, zonal pathway in purple, and unidentified pathways in yellow. Black boxes indicate times of radar observations included in this analysis.

trajectory method $80 \%$ of the time. Times that did not agree between the two methodologies included transitionary times, where SB and SW flows are shown to alternate during IOPs (Fig. 4) and likely contained hybrid flow characteristics. Additionally, during SNOWIE, we observed that SB and SW pathways were more common in January and February, and the zonal pathway was most common in March.

Moisture fluxes entering the Payette Mountains associated with each pathway show some dependence on the origin latitude of the trajectory, defined as the point where the back trajectory terminates (Fig. 3b). In general, the farther equatorward origin, the higher IVT at PJ. The origin latitudes of trajectories correlates to IVT with an $r$ value of -0.39 , explaining $15.5 \%$ of the variance in IVT at PJ $(p<0.05)$. While many other factors are likely involved in determining IVT at PJ, it appears that the farther equatorward origin of air in SB flow is partially responsible for larger IVT observed at PJ. Some of the SB trajectories originate south of $30^{\circ} \mathrm{N}$ latitude, which suggest that airflow can move quasi meridionally from the tropics, through the CV to Idaho (Fig. 3a) and these trajectories provided some of the largest values of IVT at PJ (Fig. 3b). Due to differing source regions, less moisture is transported to $\mathrm{PJ}$ in SW and zonal flow, while SB trajectories have higher average moisture flux. Mean IVT at PJ is $180 \mathrm{~kg} \mathrm{~m}^{-1} \mathrm{~s}^{-1}$ in SB flow, $138 \mathrm{~kg} \mathrm{~m}^{-1} \mathrm{~s}^{-1}$ in SW flow, and $131 \mathrm{~kg} \mathrm{~m}^{-1} \mathrm{~s}^{-1}$ in zonal flow. While atmospheric river conditions are well defined at landfall, moisture fluxes associated with inland propagating atmospheric rivers can diverge greatly. In our cases, atmospheric river conditions with IVT $\geq 250 \mathrm{~kg} \mathrm{~m}^{-1} \mathrm{~s}^{-1}$ were observed at PJ in 8 of 65 trajectories $(12.3 \%)$ in SB flow, 3 of 60 trajectories (5.0\%) in SW flow, and 1 of 26 trajectories $(3.8 \%)$ in zonal flow. However, the question remains whether the higher IVT at $\mathrm{PJ}$ in SB flow is mainly related to how pathways dictate the origin of air masses or if the moisture flux is also better preserved during SB flow as it travels through the $\mathrm{CV}$ and over lower terrain between Lake Tahoe and the Burney Gap compared to SW and zonal flow.

To address this question, the vertical structure of moisture flux was averaged across all back trajectories at the first point along the coast and at PJ using the HRRR analyses and accompanied by the mean IVT in each pathway (Fig. 5). Mean IVT values follow a similar hierarchy along the coast and at PJ, with the highest IVT in SB flow, followed by SW and zonal flow. However, the percentage of average coastal IVT that makes it to PJ varies from that hierarchy. SB flow retained the highest percentage of coastal IVT $(49.9 \%)$, followed by zonal flow (45.7\%), and SW flow (43.6\%). Smith et al. (2010) observed similar differences in drying ratios across Northern California with a smaller fraction of water vapor being removed by the Coast Range and Sierra Nevada when a Sierra barrier jet was evident. In addition, atmospheric moisture has been shown to be better conserved when air flows through gaps in terrain, when moisture transport is larger, and when surface temperatures are larger (Kirshbaum and Smith 2008; Smith et al. 2010; Rutz et al. 2015; Mueller et al. 2017), which all align with SB flow (see temperature discussion in section 3b). However, other factors must be considered, including coastal moisture flux at other altitudes that are subject to different moisture pathways.

Coastal moisture flux was much larger at midlevels (3$6 \mathrm{~km}$ MSL) in SB flow compared to SW and zonal flow (Fig. 5a). Flow at these levels was likely not entrained into the Sierra barrier jet due to the altitude and this moisture flux may be altered differently by the terrain and precipitation processes. For example, Strong moisture flux at midlevels has been shown to increase precipitation amount in the Lake Tahoe region and increase spillover precipitation to the leeside of the Sierra Crest (Kaplan et al. 2009; Backes et al. 2015). It is possible that the stronger midlevel moisture flux along the coast in SB flow plays some role in its ability to penetrate farther inland to PJ. Some insight on this speculation may be provided by the patterns in coastal and PJ moisture flux profiles in SW and zonal flows. In both locations we observed higher (lower) moisture flux below (above) $4 \mathrm{~km}$ MSL in SW flow compared to zonal flow (Fig. 5). To gain 
a)



b)

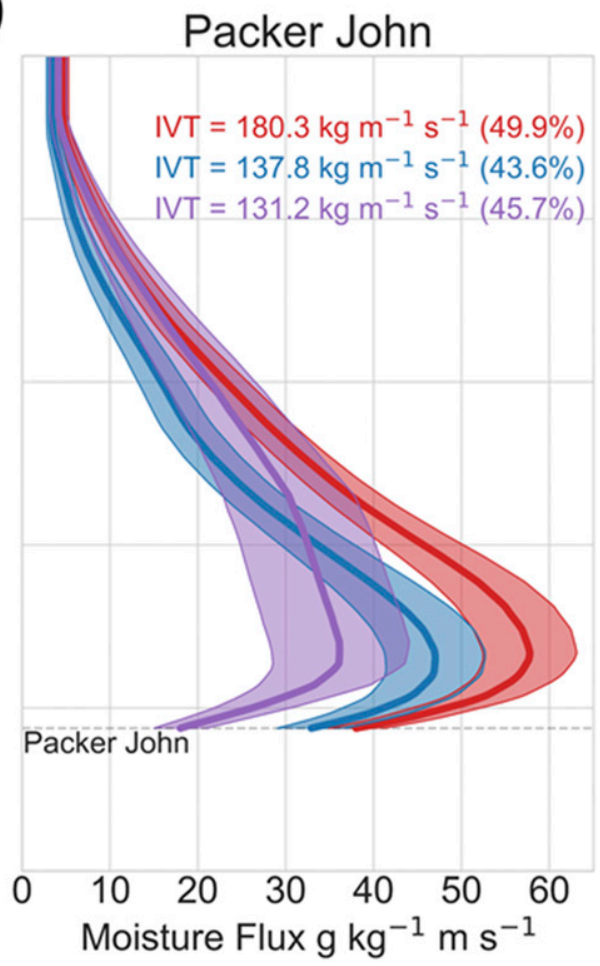

FIG. 5. Vertical profiles of mean moisture flux (solid lines) with $95 \%$ confidence interval around the mean (shaded) using HRRR data at the grid point nearest to (a) the location of the backward trajectory once over the ocean and (b) PJ. The height of PJ in the HRRR model is $1750 \mathrm{~m}$ MSL as shown in (b). Mean IVT values are shown for (a) coastal and (b) PJ with the percentage of remaining coastal IVT.

a more complex understanding of the inland penetration of moisture flux in each pathway and at multiple heights in the atmosphere, we suggest numerical weather prediction model simulations similar to Smith et al. (2010).

To provide large-scale context of the moisture transport observed in the trajectory analysis and vertical distributions of moisture flux, we used a composite snapshot of large-scale flow and horizontal moisture transport and identified different flow patterns associated with each pathway (Fig. 6). SB and SW flow display very similar patterns in the $500-\mathrm{hPa}$ geopotential height field (Figs. 6a,b). The main differences are the closed 5280-m isohypse, a more amplified wave pattern, and more southwesterly flow on the leading edge of the trough associated with SB flow. Guided by the more amplified flow in the SB pathway, higher composite IVT is shifted farther south and oriented more southwesterly compared to SW flow, and higher IVT is observed making landfall and traveling through the $\mathrm{CV}$, lower terrain between Lake Tahoe and the Burney Gap, and to PJ. In SW flow, weaker IVT at landfall is unable to penetrate large quantities of moisture flux as far inland as SB flow. In contrast, isohypses in zonal flow show a weaker trough positioned farther to the north and zonal flow extending upstream to $150^{\circ} \mathrm{W}$ (Fig. 6c). Zonal flow has large IVT making landfall in Oregon but is weakened substantially by the Coast and Cascade Ranges, and, therefore, limits the amount of moisture flux arriving at PJ. However, zonal IVT does not follow the $500-\mathrm{hPa}$ contours and much of the moisture flux is confined to lower levels (Fig. 5a). In addition to horizontal moisture transport, moisture flux convergence can also be important for understanding local moisture flux quantities and precipitation patterns. Vertical profiles of moisture flux convergence (not shown) were calculated using Banacos and Schultz [(2005); their Eq. (5)] between the HRRR model grid point nearest PJ and the grid point nearest each backward trajectory $1 \mathrm{~h}$ prior to arrival at PJ. The only statistically significant layer of moisture flux convergence was in SB flow, extending from the surface up to $3 \mathrm{~km}$ MSL with the maximum mean value of $7 \times$ $10^{-4} \mathrm{~g} \mathrm{~kg}^{-1} \mathrm{~s}^{-1}$ at $1700 \mathrm{~m}$ MSL. The HRRR and NARR datasets are useful for providing the larger-scale prospective of moisture transport from the Pacific to the Payette Mountains. However, these datasets may not be able to fully resolve local effects of terrain on the thermodynamic and dynamics. Therefore, we use 

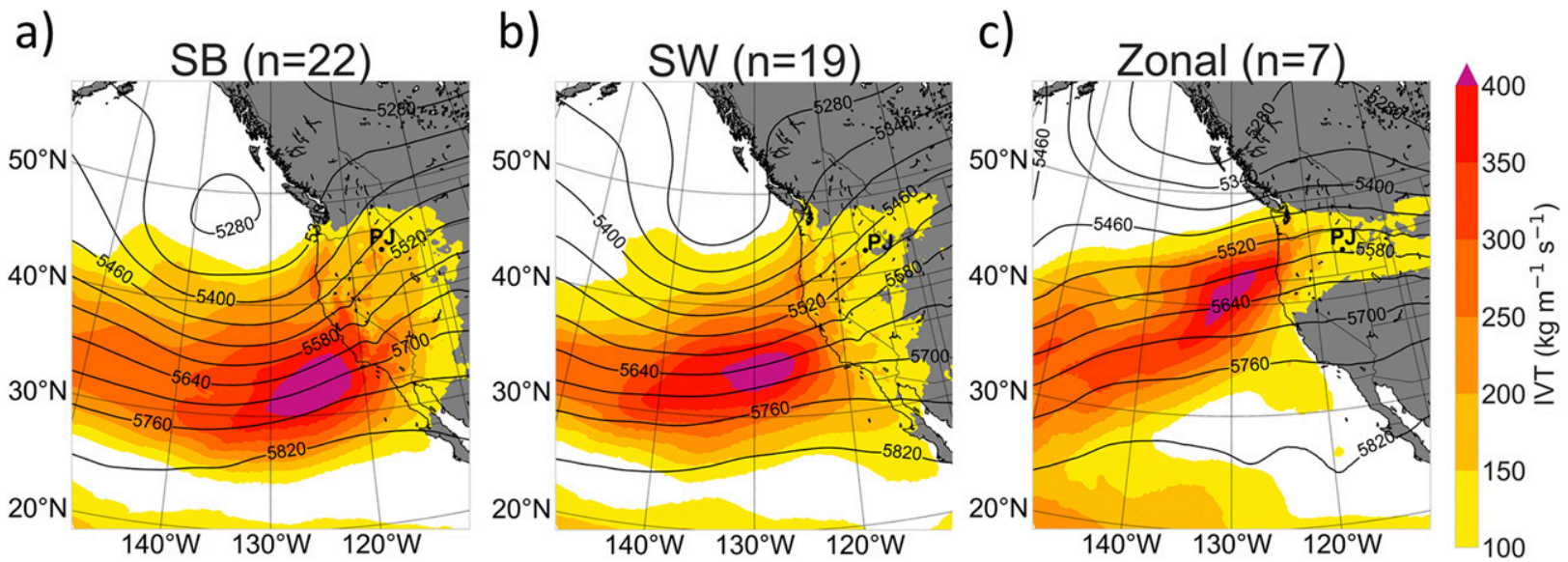

FIG. 6. Composite 500-hPa heights (m MSL; solid black) and IVT (color coded) for (a) SB, (b) SW, and (c) zonal pathways using NARR data. Number of NARR analyses used in the composite are indicated.

observations in the Payette Mountains to further differentiate local atmospheric conditions that result from the pathways.

\section{b. Observations of thermodynamics and dynamics}

In this section, we analyze how the large-scale moisture fluxes associated with different pathways affect regional thermodynamic and dynamic conditions in the Payette Mountains. Observed surface air temperatures were similar in all three pathways, but as height increases, zonal flow temperatures immediately become colder than SB and SW flow and temperatures in SW flow become colder than SB flow above $\sim 1.8 \mathrm{~km}$ MSL (Fig. 7a). On average, SB flow was warmer than SW (zonal) flow by $1^{\circ}-4^{\circ} \mathrm{C}\left(3^{\circ}-8^{\circ} \mathrm{C}\right)$ between 2 and $8 \mathrm{~km}$ MSL. Following the warmer temperatures, SB flow had on average $0.2-0.5 \mathrm{~g} \mathrm{~kg}^{-1}\left(0.2-0.9 \mathrm{~g} \mathrm{~kg}^{-1}\right)$ more moisture than SW (zonal) flow between 2 and $8 \mathrm{~km} \mathrm{MSL} \mathrm{(Fig.} \mathrm{7b).}$ Differences in specific humidity were largest at low levels (2-4 km MSL) where large quantities of moisture exist. At this level, lower moisture content in zonal flow was at least partially responsible for the weaker lowlevel moisture flux shown by the HRRR model (Fig. 5b).

Rawinsondes observations show that wind speed was also partially responsible for the weaker low-level moisture flux in zonal flow (Fig. 8a). Wind was calm near the surface and channeled southerly through the valley in all pathways (Figs. 1b and 8a). With increasing height, winds strengthened and veered south-southwesterly in SB flow, southwesterly in SW flow, and west-southwesterly in zonal flow starting at the height of PJ. At $3.5 \mathrm{~km}$ MSL upward, winds continued to veer to southwesterly in SB and SW flow and westerly in zonal flow. Differences in wind speed were most pronounced at $2-4 \mathrm{~km}$ MSL, where SB (SW) winds averaged $18.4 \mathrm{~m} \mathrm{~s}^{-1}\left(16.4 \mathrm{~m} \mathrm{~s}^{-1}\right)$, and zonal winds averaged $12.5 \mathrm{~m} \mathrm{~s}^{-1}$. These weaker low-level winds in zonal flow along with lower moisture content result in the lower moisture flux at low levels (Figs. $5 b$ and $8 b$ ).

Despite the small sample size of soundings used to compute average moisture flux, we observed similar IVT and vertical structure of moisture flux as the HRRR model (Figs. 5b and 8b). Sounding-based mean IVT for SB flow was $190.6 \mathrm{~kg} \mathrm{~m}^{-1} \mathrm{~s}^{-1}$ (vs. $180 \mathrm{~kg} \mathrm{~m}^{-1} \mathrm{~s}^{-1}$ from the HRRR model), $140.6 \mathrm{~kg} \mathrm{~m}^{-1} \mathrm{~s}^{-1}$ for SW flow $\left(138 \mathrm{~kg} \mathrm{~m}^{-1} \mathrm{~s}^{-1}\right.$ model based), and $141.5 \mathrm{~kg} \mathrm{~m}^{-1} \mathrm{~s}^{-1}$ for zonal (131 $\mathrm{kg} \mathrm{m}^{-1} \mathrm{~s}^{-1}$ model based). SB flow exhibited stronger moisture flux throughout the profile with an average maximum $>60 \mathrm{~g} \mathrm{~kg}^{-1} \mathrm{~m} \mathrm{~s}^{-1}$. Similar structure was observed in SW flow, but with an average maximum just over $50 \mathrm{~g} \mathrm{~kg}^{-1} \mathrm{~m} \mathrm{~s}^{-1}$. Moisture flux in zonal flow was weak at low levels, barely exceeding $40 \mathrm{~g} \mathrm{~kg}^{-1} \mathrm{~m} \mathrm{~s}^{-1}$ on average but decreases little with height until $\sim 5 \mathrm{~km}$ MSL where it paralleled SB flow moisture flux and exceeded that of SW flow. Studies on orographic precipitation have shown that larger moisture flux at low levels correlates to larger precipitation rates (Neiman et al. 2002, 2009). Applying this relationship, we hypothesize that higher precipitation amounts occur in SW flow compared to zonal flow despite similar IVT values, which is discussed in section $3 \mathrm{c}$.

In addition to differences in moisture flux, atmospheric stability also affects the amount and distribution of precipitation. We present static stability in the form of squared moist Brunt-Väisälä frequency $\left(N_{m}^{2}\right.$, Fig. 8c) and dynamic stability in the form of percentage of soundings that exhibit a Richardson number (Ri) less than the critical value of 0.25 in each pathway (Fig. $8 d$ ). $\mathrm{Ri}<0.25$ indicates dynamic instabilities, conditions which have been shown to induce Kelvin-Helmholtz overturning cells that can enhance fallout of precipitation (Houze and Medina 2005; 
a)



b)

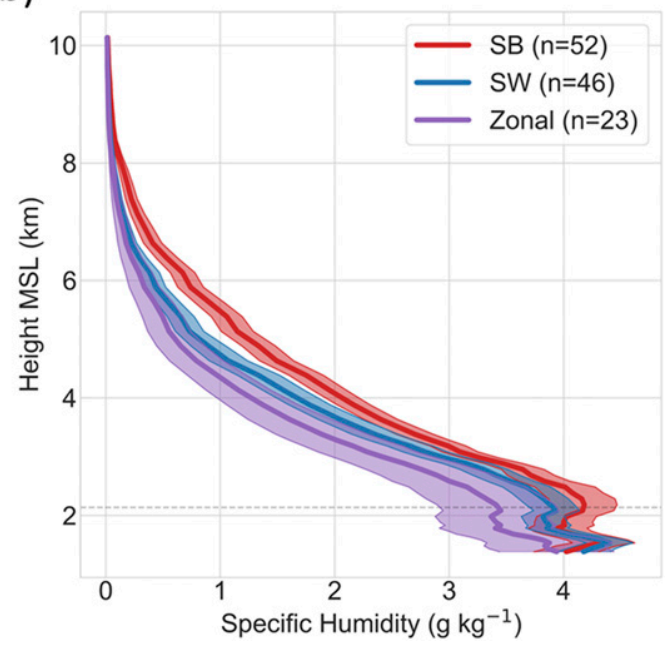

FIG. 7. Vertical profiles of mean (a) temperature and (b) specific humidity (solid lines) with $95 \%$ confidence interval around the mean (shaded) using the MWR data. The height of PJ is shown by the gray dashed lines. Total hours of data used to calculate means are indicated.

Medina and Houze 2015). For all pathways, static stability was largest near the surface (Fig. 8c) where temperature inversions exist between the cold air trapped in the valley and the relatively warmer air flowing aloft (Fig. 7a). Above PJ mountain the air mass was, on average, near moist neutral $\left(N_{m}^{2}<1 \times 10^{-4} \mathrm{~s}^{-2}\right)$ in each of the pathways. This generally weak static stability allows for small vertical wind shears to be sufficient for driving dynamic instabilities. Thus, we observed $\mathrm{Ri}<0.25$ in $\sim 60 \%$ of all the soundings, regardless of pathway (Fig. 8d). The frequency was $10 \%-20 \%$ higher between 1.5 and $2.5 \mathrm{~km}$ MSL in a shear layer where airflow trapped in the valleys was decoupled from overriding flow from the pathways. The increased dynamic instability in this layer may act to increase snowfall to a greater extent over valleys than mountains ranges that exceed this layer in height. Nonetheless, these data suggest Kelvin-Helmholtz overturning cells are likely a common phenomenon in the Payette Mountains and we conclude that static and dynamic instabilities and their effects on snowfall are independent of pathways.

\section{c. Cloud structure, snow intensity, and distribution}

In this section, we use observations of echo top heights and $Z_{e}$ from PPI volume scans to understand differences in cloud structure and snowfall rates in each pathway. There were 241 volume scans in SB flow totaling $29.7 \mathrm{~h}$, 308 volumes in SW flow totaling $31.1 \mathrm{~h}$, and 121 volumes in zonal flow totaling $10.8 \mathrm{~h}$. Echo top heights in SB flow were on average the highest with a mean of $5.1 \mathrm{~km} \mathrm{MSL}$, SW flow echo tops averaged $4.4 \mathrm{~km}$ MSL, and zonal flow echo tops averaged $3.9 \mathrm{~km}$ MSL (Fig. 9). Echo top height distributions in SB flow also exhibit a large tail of higher echo top heights compared to SW and zonal flow indicating that the deepest storms were associated with this pathway. These higher echo tops during SB flow suggest that snow fell through a deeper cloud layer, which also contained higher moisture content (Fig. 7b), and provided the potential for snowflakes to aggregate, accrete, and in general produce more snowfall during this pathway.

In accordance with the average echo top height, SB flow produced the largest average $Z_{e}$, followed by SW flow and zonal flow (Figs. 10a-c). The $Z_{e}$ in SB flow averaged $20-25 \mathrm{~dB} Z_{e}$, with localized regions of $Z_{e}>$ $25 \mathrm{~dB} Z_{e}$ and $Z_{e}<20 \mathrm{~dB} Z_{e}$ (Fig. 10a). Areas of highest reflectivity are found in the upwind valleys to the west and southwest of PJ (Fig. 10d - area 1), 10-20 km north of PJ, and in the northern Garden Valley (Fig. 10d - area 2). Areas of $Z_{e}<20 \mathrm{~dB} Z_{e}$ are abundant in the northeastern and eastern edges of the radar domain. These areas are likely the result of partial beam blockage from the terrain. As the radar beam widens farther from the radar, the effect of partial beam blockage can become larger and, thus, we expect this issue to be maximized at the periphery of the radar range and behind large orographic barriers. With fixed terrain and elevation angle beams for all volume scans, we can assume this reduction is consistent in each pathway and we compare them equally. Nonetheless, during SB flow, mean $Z_{e}$ was observed to be relatively large and uniform across the lower terrain upwind and downwind of the radar compared to the distribution in other pathways.

Mean $Z_{e}$ in SW flow was lower than in SB flow across the majority of the domain and produced a different 

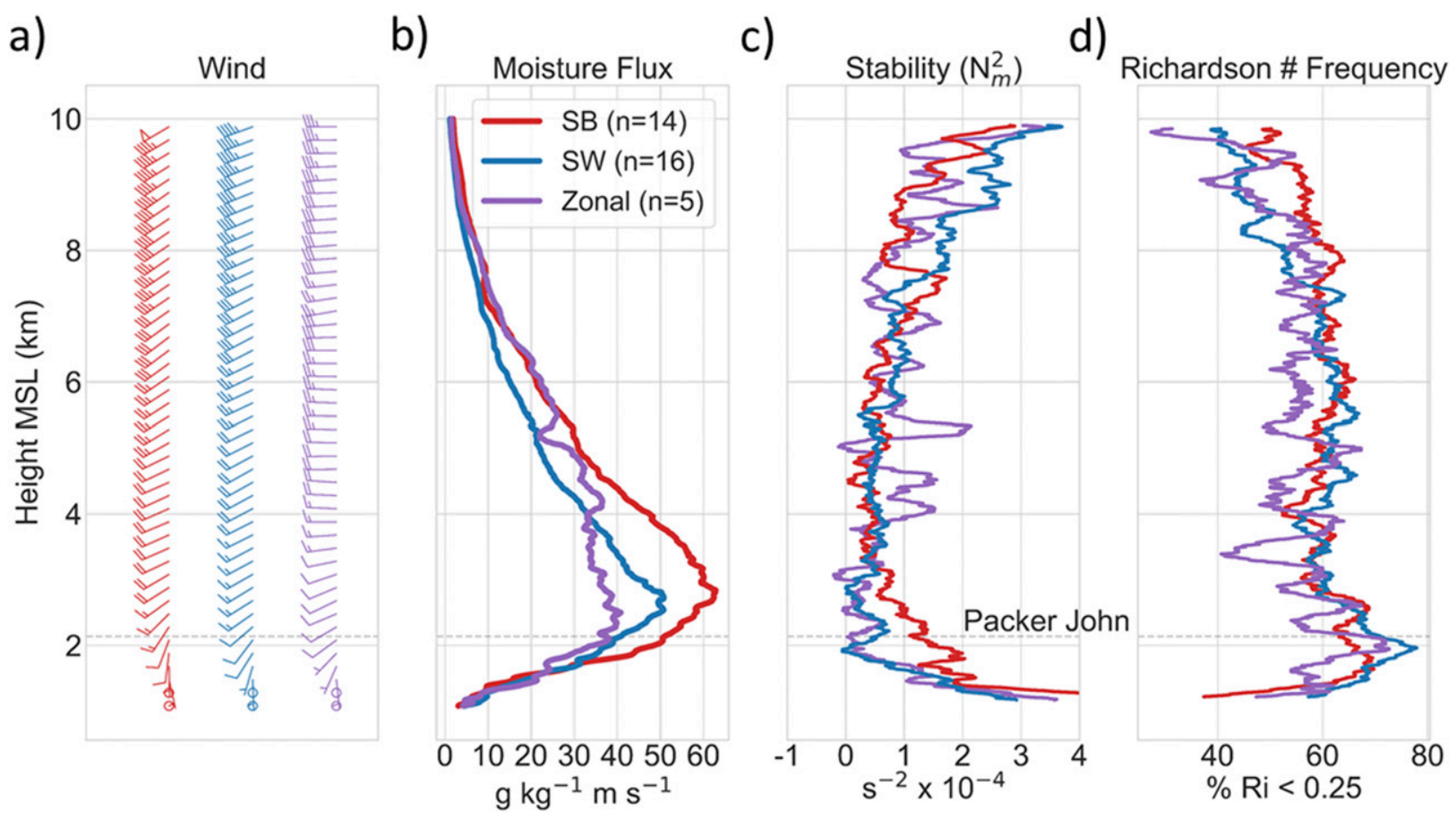

FIG. 8. Vertical profiles of mean (a) wind barbs $\left(\mathrm{m} \mathrm{s}^{-1}\right.$; short barb $=5 \mathrm{~m} \mathrm{~s}^{-1}$, long barb $=10 \mathrm{~m} \mathrm{~s}^{-1}$, flag $\left.=50 \mathrm{~m} \mathrm{~s}^{-1}\right),(\mathrm{b})$ moisture flux, (c) moist static stability, and (d) percentage of soundings with $\mathrm{Ri}<0.25$ using rawinsonde observations. The height of $\mathrm{PJ}$ is shown by the gray dashed lines. Wind barbs are shown at 200-m intervals in (a), moisture flux at 10-m intervals in (b), and static stability and Ri are shown with a 200- and 300-m running average in (c),(d), respectively. Number of soundings used in mean computation are indicated in (b).

distribution pattern (Fig. 10b). Opposed to the pattern we observed in SB flow, SW flow $Z_{e}$ decreased beyond $25 \mathrm{~km}$ west of PJ. Areas of $Z_{e}=12.5-17.5 \mathrm{~dB} Z_{e}$ in the upwind valleys are substantially less than areas with $Z_{e}=17.5-22.5 \mathrm{~dB} Z_{e}$ observed east of the first orographic barriers $\sim 25 \mathrm{~km}$ west of PJ. Higher $Z_{e}$ was observed in the general area to the east of PJ, in Garden Valley, as well as to the north. The highest $Z_{e}$, exceeding $22.5 \mathrm{~dB} Z_{e}$, in $\mathrm{SW}$ flow was observed in areas just below $1500 \mathrm{~m}$ MSL in Garden Valley in areas that are upwind of larger orographic barriers with peaks just below $2500 \mathrm{~m}$ MSL. In general, we find that $Z_{e}$ in SW flow is more closely tied to areas around higher terrain than observed in SB flow indicating that precipitation is primarily orographically generated.

Mean $Z_{e}$ in zonal flow depicts a similar pattern to SW flow, but with lower $Z_{e}$ (Fig. 10c). $Z_{e}$ was less than $10 \mathrm{~dB} Z_{e}$ over the lowest terrain $40-50 \mathrm{~km}$ to the southwest of $\mathrm{PJ}$ and is $10-20 \mathrm{~dB} Z_{e}$ over High Valley (Fig. 10d; area 3 ) and other higher terrain closer to PJ. The highest $Z_{e},\left(>17.5 \mathrm{~dB} Z_{e}\right)$ was observed to the north of $\mathrm{PJ}$ in areas of the Lake Cascade Valley (Fig. 10d; area 4), and in the northeastern corner of Garden Valley. In general, precipitation is strongly modulated by the terrain as $Z_{e}$ was largest in zonal flow to the east of $\mathrm{PJ}$ in areas of higher terrain compared to the upwind valleys.
To better detail which elevations received more radar estimated snowfall in each pathway, we calculated the surface area of the terrain and the accumulated linearized $Z_{e}$ between 700 and $2700 \mathrm{~m}$ at intervals of $100 \mathrm{~m}$ (Fig. 11). Using this metric, we find that SB flow had the highest accumulated $Z_{e}$ at all elevations while zonal flow

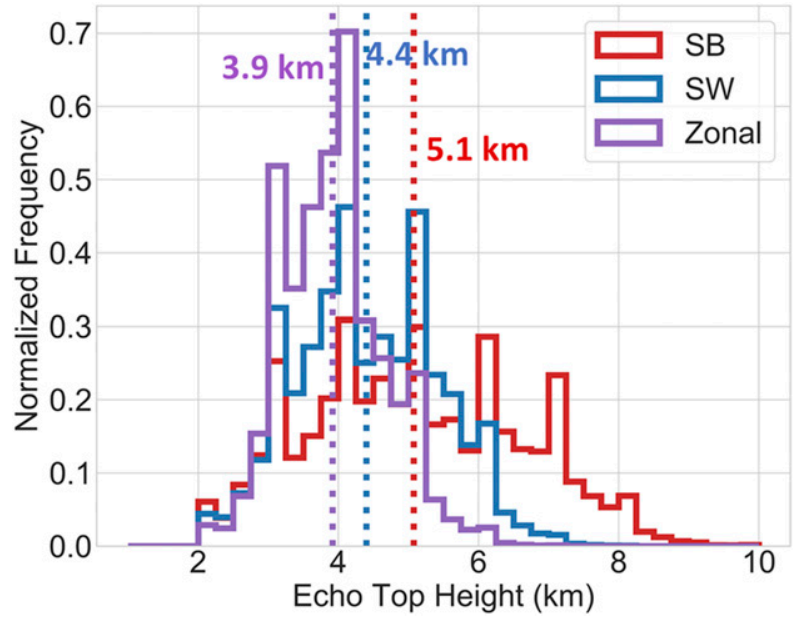

FIG. 9. Normalized frequency of echo top heights for SB, SW, and zonal flow. Mean echo top heights are shown in vertical dashed lines. 

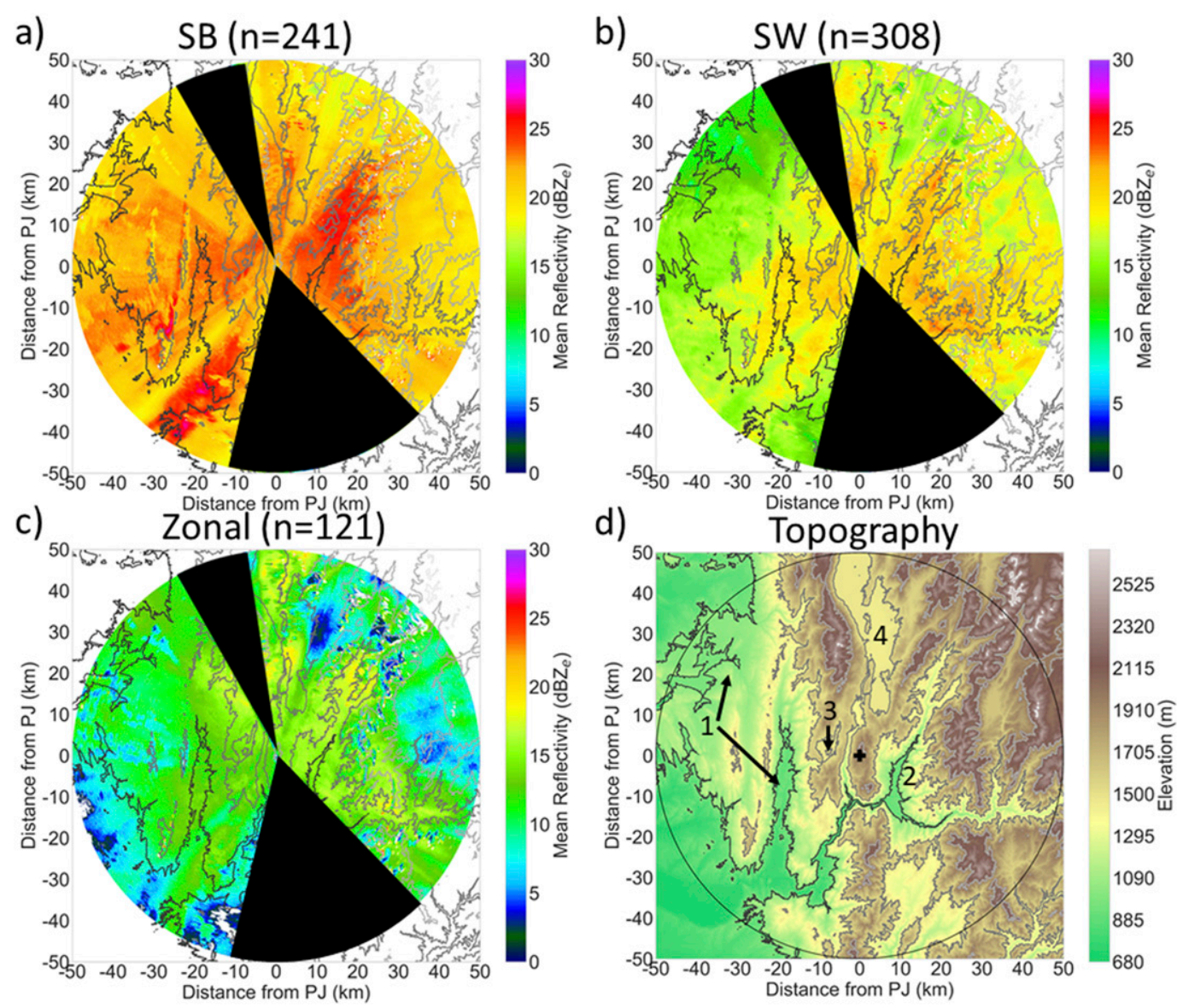

FIG. 10. Time-weighted mean equivalent reflectivity (color coded) and 500-m elevation contours (grayscale) during (a) SB, (b) SW, and (c) zonal pathways observed by the PJ radar. (d) Color-coded topographic map with 500-m elevation contours (grayscale). (a)-(c) Blacked out regions within the radar range show areas of beam blockage. Sample size indicates the number of volume scans used in mean computation. (d) Maximum radar range of $50 \mathrm{~km}$ is indicated by black circle. Terrain features discussed in the text include 1) upwind valleys, 2) Garden Valley, 3) High Valley, and 4) Lake Cascade Valley.

had the least. SB flow produced the most accumulated $Z_{e}$ between $1000-1100 \mathrm{~m}$ and $1400-1500 \mathrm{~m}$, which includes the terrain features shown in Fig. 10d. SW flow produced substantially less $Z_{e}$ between 1000 and $1100 \mathrm{~m}$ compared to $1400-1500 \mathrm{~m}$. Zonal flow generated the least amount of accumulated $Z_{e}$ at all elevations compared to $\mathrm{SB}$ and $\mathrm{SW}$ flow. However, $Z_{e}$ also maximized between 1400 and $1500 \mathrm{~m}$ in zonal flow similar to SW flow. During SW and zonal flow, largest linearized $Z_{e}$ accumulations were observed between 1400 and $1500 \mathrm{~m}$, which is about twice the amount observed between 1000 and $1100 \mathrm{~m}$.

Accumulating $Z_{e}$ over all SNOWIE IOPs, we estimate that SB flow produced $66.6 \%$ of the total accumulated $Z_{e}$ in $41.5 \%$ of the time. Similarly, SW (zonal) flow generated $30.6 \%(2.8 \%)$ of the total accumulated $Z_{e}$ in $43.4 \%(15.1 \%)$ of the time. Thus, we conclude that airflow blocked and redirected northward by the Sierra Nevada and through lower terrain between Lake Tahoe and the Burney Gap (SB flow) was associated with an estimated two-thirds of the radar-estimated snowfall observed during SNOWIE and frequent trajectories through this pathway ( $42 \%$ of all trajectories during SNOWIE) was likely a key factor for the above average snowfall that accumulated in the Payette Mountains during SNOWIE.

\section{Discussion}

The analysis presented in this paper applies results from moisture pathway studies over the Intermountain West (e.g., Alexander et al. 2015; Rutz et al. 2015) to radar-estimated snow intensity and distribution for a localized region of the Intermountain West in the Payette Mountains of Idaho. We expand upon these studies by computing hourly trajectories rather than daily trajectories, as done in previous studies, and show that in most 


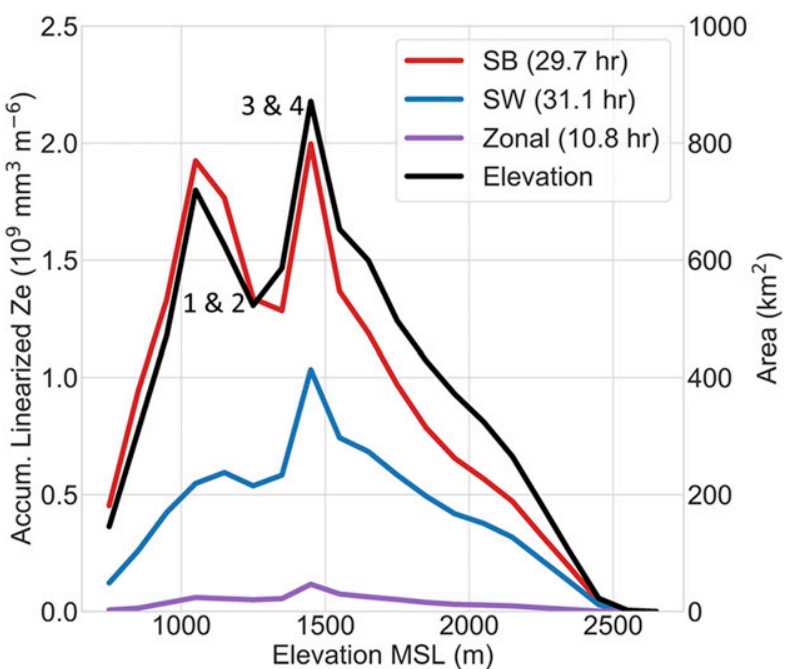

FIG. 11. Accumulated, time-weighted, linearized equivalent reflectivity for SB (red line), SW (blue line), and zonal flow (purple line) as a function of height and surface area (black line). Numbers 1-4 correspond to the terrain features shown in Fig. 10d and discussed in the text.

cases $(71 \%$ of IOPs) moisture pathways vary within a single storm system (time scale of $3-11 \mathrm{~h}$ ) as they are driven by eastward propagating upper-level troughs embedded in the polar jet stream (Figs. 4 and 6). In JanuaryFebruary, when the jet stream is typically located farther south, SB and SW flow were observed as the prevalent pathways and were associated with landfalling storms in Southern and central California (Figs. 4 and 6a,b). In 2017, storms with SB and SW flow brought heavy precipitation to California and eradicated the persistent drought of 2012-16 (Wang et al. 2017; Ullrich et al. 2018). The authors acknowledge that January-February 2017 represents anomalous jet stream activity, similar to January and February 1998, which also produced anomalously high precipitation in California (Wang et al. 2017). Despite the anomalous season captured by this study, the results of pathway frequency are generally consistent with the frequency of atmospheric rivers in central and Southern California as shown by Rutz et al. (2014). While the $\sim 2$-month sample of moisture pathways presented in this study may not be indicative of seasonal or longerterm populations, this portion of the winter season is remarkable to study given the 50th percentile of seasonal snowfall to begin the SNOWIE project and the 95th percentile by its conclusion (Tessendorf et al. 2019).

Airflow following the SB pathway was more efficient in transporting large quantities of IVT to the Payette Mountains than the SW and zonal pathways. IVT observed at PJ was similar in SW and zonal flows, and $\sim 35 \%$ higher in SB flow, which includes $50 \%$ of the coastal SB flow IVT compared to $44 \%$ (46\%) in SW (zonal) flow. We find that the higher amplitude troughs associated with SB flow and higher IVT observed inland are consistent with the analysis of Rutz et al. (2015). Despite similar IVT in SW and zonal flows in both the HRRR model and observations, higher $Z_{e}$ was observed in SW flow compared to zonal flow. We believe the difference in $Z_{e}$ is the direct result of the vertical structure of the moisture flux. Stronger moisture flux at low levels (2-4 km MSL, Figs. 5b and $8 b$ ) was observed in SW flow and since both SW and zonal flows are primarily dependent on orographic forcing (Figs. 10b,c), the low-level moisture flux impinging on the mountain range is directly related to the forced ascent of moist air (Neiman et al. 2002, 2009). Correlation coefficients between moisture flux at varying heights and linearized accumulated $Z_{e}$ were tested and it was found that the correlation coefficients were maximized $(r>0.64)$ around $2 \mathrm{~km}$ MSL for SW and zonal flows and were larger than IVT $-Z_{e}$ correlations $(r<0.44)$. Therefore, at least for orographically induced precipitation in the Payette Mountains, it appears that low-level moisture flux is more indicative of precipitation amount than IVT. Further, the pathways analysis presented in this study only focuses on air trajectories that arrived at $3 \mathrm{~km}$ MSL above PJ. Mid- and upper-level flows in the Payette Mountains likely take different pathways, and, based on their altitude, may be unaffected by upstream terrain. Therefore, while SW and zonal pathways may have little effect on differences in IVT, the low-level moisture flux is dramatically different in these pathways and translates to disparate snowfall amounts. Besides orographic lift, there are potentially many microphysical and dynamical processes (e.g., seeder-feeder mechanism, cloud-top generating cells) involved that convert the enhanced low-level moisture flux into orographic precipitation. These processes are not addressed here.

The SB and SW pathways were the most efficient in transporting low-level moisture flux to the Payette Mountains and in producing snowfall during SNOWIE. Both of these pathways were associated with IVT maxima offshore of central and Southern California. The IVT maxima in SB flow was located in the $30^{\circ}-35^{\circ}$ latitude band and in SW flow in the $32^{\circ}-35^{\circ}$ latitude band (Figs. 6a,b). Future climate simulations suggest a possible increase in landfalling atmospheric rivers in the $32^{\circ}-35^{\circ}$ latitude band (Shields and Kiehl 2016), which could increase the frequency of SB and SW moisture pathways into the Payette Mountains. Given that the SB and SW pathways were the most efficient in producing snowfall during SNOWIE, an increase in pathway frequency could potentially lead to an increase in snowfall in the Payette Mountains. However, already warm temperatures often associated with SB and SW flow events (Fig. 7a) are 
predicted to become warmer in future climate scenarios, shifting the rain-snow line higher in altitude (Mahoney et al. 2018) and adding complexity to the prediction of future snowfall. In addition, many other factors including atmospheric river frequency, intensity, and orientation (Hughes et al. 2014; Warner et al. 2015; Hecht and Cordeira 2017; Mahoney et al. 2018), frequency of nonatmospheric river storms, and changes in temperature, moisture, and microphysical processes (Pavelsky et al. 2012; Siler and Roe 2014; Morales et al. 2019; Napoli et al. 2019) are important and must be considered in future precipitation projections. However, we demonstrate that moisture pathways are an important factor in determining localized snowfall amounts and distributions and can be useful in understanding interannual snowpack variability and future precipitation.

\section{Conclusions}

This paper presents a multiscale analysis of moisture pathways and moisture fluxes into Payette Mountains of Idaho and their role on local atmospheric conditions and snowfall distribution between 7 January and 17 March 2017. We identified three common pathways of air being transported from the Pacific Ocean to Idaho: Sierrablocked, southwest, and zonal flow. For the three pathways, we then investigated atmospheric conditions and snowfall amounts and distributions using observations from an MWR, soundings and a scanning X-band radar. The main findings are as follows:

- During SNOWIE, SB flow was the most common during precipitating systems (41.8\%), followed by SW flow $(37.3 \%)$ and zonal flow (16.5\%).

- Moisture pathways are dynamic and often change during the course of a precipitation event.

- The Sierra barrier jet helps source moist air more directly from the tropics and transport it northward to Idaho and also reduces the moisture flux by a smaller percentage compared to other flows.

- SB flow was associated with warmer temperatures, more moisture, larger IVT and low-level moisture flux, and deeper cloud systems in the Payette Mountains of Idaho compared to other flows.

- SB flow accounted for two-thirds of the total accumulated linearized $Z_{e}$ observed during SNOWIE, despite only accounting for $41.5 \%$ of the total precipitating time used in the analysis.

- SB flow was associated with higher accumulated linearized $Z_{e}$ at all elevations, but especially at lower elevations in the upwind valleys.

- Despite similar modeled and observed mean IVT values in SW and zonal flow, less moisture and weaker winds at low levels in zonal flow resulted in weaker low-level moisture flux and contributed to the drastically lower mean $Z_{e}$ in zonal flow.

Since seasonal snowfall in the American West can vary from year to year based on frequency, intensity, orientation, and landfall location of winter storms, the authors recommended that more seasons are evaluated to further improve our understanding of the role moisture pathways have on snowfall in Payette Mountains of Idaho on an interseasonal basis and to better predict how seasonal snowfall may differ in a changing climate. Additionally, high-resolution numerical weather simulations of airflow in each pathway would provide enhanced detail on the role of the underlying terrain in modulating moisture transport to the Payette Mountain of Idaho. Considering Idaho's dependence on spring and summer runoff for hydropower, these findings may serve useful for short- to medium-term forecasting for water managers and in determining energy policy for the future based on climate projections of moisture pathways along with other factors.

Acknowledgments. The authors gratefully acknowledge the NOAA Air Resources Laboratory (ARL) for the provision of the HYSPLIT transport and dispersion model and/or READY website (http://www.ready.noaa.gov) used in this publication. This research was supported under NSF Grant AGS-1546963 and by the Idaho Power Company. We also thank Sarah Tessendorf of the National Center for Atmospheric Research (NCAR), Allen White of the National Oceanic and Atmospheric Administration/Earth System Research Lab (NOAA/ESRL), and Noah Molotch and Jan Lenaerts of the University of Colorado for the fruitful discussions and their input. We also acknowledge researchers and students from NCAR, University of Wyoming, University of Illinois Urbana-Champaign, University of Colorado Boulder, and Center for Severe Weather Research for assistance with data collection and processing. Thank you to Josh Aikins for assistance in various stages of this research.

\section{REFERENCES}

Aikins, J., K. Friedrich, B. Geerts, and B. Pokharel, 2016: Role of a cross-barrier jet and turbulence on winter orographic snowfall. Mon. Wea. Rev., 144, 3277-3300, https://doi.org/ 10.1175/MWR-D-16-0025.1.

Alexander, M. A., J. D. Scott, D. Swales, M. Hughes, K. Mahoney, and C. A. Smith, 2015: Moisture pathways into the U.S. Intermountain West associated with heavy winter precipitation events. J. Hydrometeor., 16, 1184-1206, https://doi.org/ 10.1175/JHM-D-14-0139.1. 
Archer, C. L., and K. Caldeira, 2008: Historical trends in the jet streams. Geophys. Res. Lett., 35, L08803, https://doi.org/ 10.1029/2008GL033614.

Backes, T. M., M. L. Kaplan, R. Schumer, and J. F. Mejia, 2015: A climatology of the vertical structure of water vapor transport to the Sierra Nevada in cool season atmospheric river precipitation events. J. Hydrometeor., 16, 1029-1047, https:// doi.org/10.1175/JHM-D-14-0077.1.

Banacos, P. C., and D. M. Schultz, 2005: The use of moisture flux convergence in forecasting convective initiation: Historical and operational perspectives. Wea. Forecasting, 20, 351-366, https://doi.org/10.1175/WAF858.1.

Bianco, L., K. Friedrich, J. Wilczak, D. Hazen, D. Wolfe, R. Delgado, S. Oncley, and J. K. Lundquist, 2017: Assessing the accuracy of microwave radiometers and radio acoustic sounding systems for wind energy applications. Atmos. Meas. Tech., 10, 1707-1721, https://doi.org/10.5194/amt-10-1707-2017.

Blaylock, B. K., J. D. Horel, and S. T. Liston, 2017: Cloud archiving and data mining of High-Resolution Rapid Refresh forecast model output. Comput. Geosci., 109, 43-50, https://doi.org/ 10.1016/j.cageo.2017.08.005.

Friedrich, K., J. K. Lundquist, M. Aitken, E. A. Kalina, and R. F. Marshall, 2012: Stability and turbulence in the atmospheric boundary layer: A comparison of remote sensing and tower observations. Geophys. Res. Lett., 39, L03801, https://doi.org/ 10.1029/2011GL050413.

— , and Coauthors, 2020: Quantifying snowfall from orographic cloud seeding. Proc. Natl. Acad. Sci. USA, 117, 5190-5195, https://doi.org/10.1073/pnas.1917204117.

Gimeno, L., R. Nieto, M. Vázquez, and D. A. Lavers, 2014: Atmospheric rivers: A mini-review. Front. Earth Sci., 2, 2 , https://doi.org/10.3389/feart.2014.00002.

Gourley, J. J., P. Tabary, and J. Parent du Chatelet, 2007: A fuzzy logic algorithm for the separation of precipitating from nonprecipitating echoes using polarimetric radar observations. J. Atmos. Oceanic Technol., 24, 1439-1451, https://doi.org/ 10.1175/JTECH2035.1.

Hecht, C. W., and J. M. Cordeira, 2017: Characterizing the influence of atmospheric river orientation and intensity on precipitation distributions over North Coastal California. Geophys. Res. Lett., 44, 9048-9058, https://doi.org/10.1002/ 2017GL074179.

Houze, R. A., and S. Medina, 2005: Turbulence as a mechanism for orographic precipitation enhancement. J. Atmos. Sci., 62, 3599-3623, https://doi.org/10.1175/JAS3555.1.

Hughes, M., K. M. Mahoney, P. J. Neiman, B. J. Moore, M. Alexander, and F. M. Ralph, 2014: The landfall and inland penetration of a flood-producing atmospheric river in Arizona. Part II: Sensitivity of modeled precipitation to terrain height and atmospheric river orientation. J. Hydrometeor., 15, 1954-1974, https://doi.org/10.1175/JHM-D-13-0176.1.

Kaplan, M. L., C. S. Adaniya, P. J. Marzette, K. C. King, S. J. Underwood, and J. M. Lewis, 2009: The role of upstream midtropospheric circulations in the Sierra Nevada enabling leeside (spillover) precipitation. Part II: A secondary atmospheric river accompanying a midlevel jet. J. Hydrometeor., 10, 1327-1354, https://doi.org/10.1175/2009JHM1106.1.

Kirshbaum, D. J., and R. B. Smith, 2008: Temperature and moist-stability effects on midlatitude orographic precipitation. Quart. J. Roy. Meteor. Soc., 134, 1183-1199, https:// doi.org/10.1002/qj.274.

Lakshmanan, V., K. Hondl, C. K. Potvin, and D. Preignitz, 2013: An improved method for estimating radar echo-top height
Wea. Forecasting, 28, 481-488, https://doi.org/10.1175/WAFD-12-00084.1.

Mahoney, K., D. Swales, M. J. Mueller, M. Alexander, M. Hughes, and K. Malloy, 2018: An examination on an inland-penetrating atmospheric river flood event under potential future thermodynamic conditions. J. Climate, 31, 6281-6297, https://doi.org/ 10.1175/JCLI-D-18-0118.1.

Medina, S., and R. A. Houze, 2015: Small-scale precipitation elements in midlatitude cyclones crossing the California Sierra Nevada. Mon. Wea. Rev., 143, 2842-2870, https://doi.org/ 10.1175/MWR-D-14-00124.1.

Morales, A., D. J. Posselt, H. Morrison, and F. He, 2019: Assessing the influence of microphysical and environmental parameter perturbations on orographic precipitation. J. Atmos. Sci., 76, 1373-1395, https://doi.org/10.1175/JAS-D-18-0301.1.

Mueller, M. J., K. M. Mahoney, and M. Hughes, 2017: Highresolution model-based investigation of moisture transport into the pacific northwest during a strong atmospheric river event. Mon. Wea. Rev., 145, 3861-3879, https://doi.org/ 10.1175/MWR-D-16-0466.1.

Napoli, A., A Crespi, F. Ragone, M. Maugeri, and C. Pasquero, 2019: Variability of orographic enhancement of precipitation in the Alpine region. Sci. Rep., 9, 13352, https://doi.org/ 10.1038/s41598-019-49974-5.

Nash, J., T. Oakley, H. Vömel, and L. I. Wei, 2011: WMO intercomparison of high quality radiosonde systems. IOM Rep. 107, WMO/TD-1580, 238 pp., https://www.wmo.int/pages/ prog/www/IMOP/publications/IOM-107_Yangjiang.pdf.

Neiman, P. J., F. M. Ralph, A. B. White, D. E. Kingsmill, and P. O. Persson, 2002: The statistical relationship between upslope flow and rainfall in California's coastal mountains: Observations during CALJET. Mon. Wea. Rev., 130, 1468-1492, https://doi.org/10.1175/1520-0493(2002)130<1468:TSRBUF> 2.0.CO;2

, A. B. White, F. M. Ralph, D. J. Gottas, and S. I. Gutman, 2009: A water vapour flux tool for precipitation forecasting. Water Manage., 162, 83-94, https://doi.org/10.1680/ WAMA.2009.162.2.83.

, M. Hughes, B. J. Moore, F. M. Ralph, and E. M. Sukovich, 2013: Sierra barrier jets, atmospheric rivers, and precipitation characteristics in Northern California: A composite perspective based on a network of wind profilers. Mon. Wea. Rev., 141, 4211-4233, https://doi.org/10.1175/MWR-D-13-00112.1.

— F. M. Ralph, B. J. Moore, and R. J. Zamora, 2014: The regional influence of an intense Sierra Barrier jet and landfalling atmospheric river on orographic precipitation in Northern California: A case study. J. Hydrometeor., 15, 1419-1439, https://doi.org/10.1175/JHM-D-13-0183.1.

Pavelsky, T. M., S. Sobolowski, S. B. Kapnick, and J. B. Barnes, 2012: Changes in orographic precipitation patterns caused by a shift from snow to rain. Geophys. Res. Lett., 39, L18706, https://doi.org/10.1029/2012GL052741.

Puhakka, T., 1975: On the dependence of the Z-R relation on the temperature in snowfall. Preprints, 16th Conf. on Radar Meteorology, Houston, TX, Amer. Meteor. Soc., 504-507.

Ralph, F. M., P. J. Neiman, and G. A. Wick, 2004: Satellite and CALJET aircraft observations of atmospheric rivers over the eastern North Pacific Ocean during the winter of 1997/98. Mon. Wea. Rev., 132, 1721-1745, https://doi.org/10.1175/15200493(2004)132<1721:SACAOO $>2.0 . C O ; 2$

, J. M. Cordeira, P. J. Neiman, and M. Hughes, 2016: Landfalling atmospheric rivers, the Sierra Barrier jet, and 
extreme daily precipitation in Northern California's upper Sacramento River watershed. J. Hydrometeor., 17, 1905-1914, https://doi.org/10.1175/JHM-D-15-0167.1.

, J. J. Rutz, J. M. Cordeira, M. Dettinger, M. Anderson, D. Reynolds, L. J. Schick, and C. Smallcomb, 2019: A scale to characterize the strength and impacts of atmospheric rivers. Bull. Amer. Meteor. Soc., 100, 269-289, https://doi.org/10.1175/ BAMS-D-18-0023.1.

Rolph, G., A. Stein, and B. Stunder, 2017: Real-time Environmental Applications and Display sYstem: READY. Environ. Modell. Software, 95, 210-228, https://doi.org/10.1016/j.envsoft.2017.06.025.

Rosenkranz, P. W., 1998: Water vapor microwave continuum absorption: A comparison of measurements and models. Radio Sci., 33, 919-928, https://doi.org/10.1029/98RS01182.

Rutz, J. J., W. J. Steenburgh, and F. M. Ralph, 2014: Climatological characteristics of atmospheric rivers and their inland penetration over the western United States. Mon. Wea. Rev., 142, 905-921, https://doi.org/10.1175/MWR-D-13-00168.1.

,-- , and -2015 : The inland penetration of atmospheric rivers over western North America: A Lagrangian analysis. Mon. Wea. Rev., 143, 1924-1944, https://doi.org/10.1175/MWR-D-14-00288.1.

Shaw, T. A., and Coauthors, 2016: Storm track processes and the opposing influences of climate change. Nat. Geosci., 9, 656664, https://doi.org/10.1038/ngeo2783.

Shields, C. A., and J. T. Kiehl, 2016: Atmospheric river landfalllatitude changes in future climate simulations. Geophys. Res. Lett., 43, 8775-8782, https://doi.org/10.1002/2016GL070470.

Siler, N., and G. Roe, 2014: How will orographic precipitation respond to surface warming? An idealized thermodynamic perspective. Geophys. Res. Lett., 41, 2606-2613, https:// doi.org/10.1002/2013GL059095.

Smith, B. L., S. E. Yuter, P. J. Neiman, and D. E. Kingsmill, 2010: Water vapor fluxes and orographic precipitation over Northern California associated with a landfalling atmospheric river. Mon. Wea. Rev., 138, 74-100, https://doi.org/ 10.1175/2009MWR2939.1.

Solheim, F., and J. R. Godwin, 1998: Passive ground-based remote sensing of atmospheric temperature, water vapor, and cloud liquid water profiles by a frequency synthesized microwave radiometer. Meteor. Z., 7, 370-376, https://doi.org/10.1127/ metz/7/1998/370.

_, — - E. Westwater, Y. Han, S. Keihm, K. Marsh, and R. Ware, 1998: Radiometric profiling of temperature, water vapor and cloud liquid water using various inversion methods. Radio Sci., 33, 393-404, https://doi.org/10.1029/97RS03656.

Stein, A. F., R. R. Draxler, G. D. Rolph, B. J. B. Stunder, M. D. Cohen, and F. Ngan, 2015: NOAA's HYSPLIT atmospheric transport and dispersion modeling system. Bull. Amer. Meteor. Soc., 96, 2059-2077, https://doi.org/10.1175/BAMS-D-14-00110.1.
Swales, D., M. Alexander, and M. Hughes, 2016: Examining moisture pathways and extreme precipitation in the U.S. Intermountain West using self-organizing maps. Geophys. Res. Lett., 43, 1727-1735, https://doi.org/10.1002/2015GL067478.

Tessendorf, S. A., and Coauthors, 2019: A transformational approach to winter orographic weather modification research: The SNOWIE project. Bull. Amer. Meteor. Soc., 100, 71-92, https://doi.org/10.1175/BAMS-D-17-0152.1.

Ullrich, P. A., Z. Xu, A. M. Rhoades, M. D. Dettinger, J. F. Mount, A. D. Jones, and P. Vahmani, 2018: California's drought of the future: A midcentury recreation of the exceptional conditions of 2012-2017. Earth's Future, 6, 1568-1587, https://doi.org/ 10.1029/2018EF001007.

U.S. Energy Information Administration, 2016: Idaho Electricity Profile 2016: Electric power industry generation by primary energy source, 1990 through 2016. Accessed 2019, https:// www.eia.gov/.

Wang, S., A. Anichowski, M. K. Tippett, and A. H. Sobel, 2017: Seasonal noise versus subseasonal signal: Forecasts of California precipitation during the unusual winters of 2015-2016 and 20162017. Geophys. Res. Lett., 44, 9513-9520, https://doi.org/10.1002/ 2017GL075052.

Ware, R., F. Solheim, R. Carpenter, J. Gueldner, J. Liljegren, T. Nehrkorn, and F. Vandenberghe, 2003: A multi-channel radiometric profiler of temperature, humidity and cloud liquid. Radio Sci., 38, 8079, https://doi.org/10.1029/ 2002RS002856.

Warner, M. D., C. F. Mass, and E. P. Salathé, 2015: Changes in winter atmospheric rivers along the North American west coast in CMIP5 climate models. J. Hydrometeor., 16, 118-128, https://doi.org/10.1175/JHM-D-14-0080.1.

White, A. B., P. J. Neiman, J. M. Creamean, T. Coleman, F. M. Ralph, and K. A. Prather, 2015: The impacts of California's San Francisco Bay Area gap on precipitation observed in the Sierra Nevada during HMT and CalWater. J. Hydrometeor., 16, 1048-1069, https://doi.org/10.1175/JHM-D-14-0160.1.

Wolfe, J. P., and J. R. Snider, 2012: A relationship between reflectivity and snow rate for a high-altitude S-band radar. J. Appl. Meteor. Climatol., 51, 1111-1128, https://doi.org/ 10.1175/JAMC-D-11-0112.1.

Xu, G., R. Ware, W. Zhang, G. Feng, K. Liao, and Y. Liu, 2014: Effect of off-zenith observations on reducing the impact of precipitation on ground-based microwave radiometer measurement accuracy. Atmos. Res., 140-141, 85-94, https:// doi.org/10.1016/j.atmosres.2014.01.021.

Zhu, Y., and R. E. Newell, 1998: A proposed algorithm for moisture fluxes from atmospheric rivers. Mon. Wea. Rev., 126, 725-735, https://doi.org/10.1175/1520-0493(1998)126<0725: $\mathrm{APAFMF}>2.0 . \mathrm{CO} ; 2$. 